\title{
Electrochemistry of surface wired cytochrome c and bioelectrocatalytic sensing of superoxide
}

\author{
SUSMITA BEHERA, RAMENDRA SUNDAR DEY, MANAS KUMAR RANA and \\ C RETNA RAJ* \\ Department of Chemistry, Indian Institute of Technology, Kharagpur 721 302, India \\ e-mail: retnaraj.c@gmail.com
}

MS received 28 January 2012; revised 17 June 2012; accepted 25 July 2012

\begin{abstract}
Electrochemistry of cytochrome c (Cyt-c) wired on an electrode modified with the self-assemblies of 4,4'-dithio-dibutyric acid (DTB) and 2-pyrazineethane thiol (PET) by covalent and electrostatic binding and the amperometric sensing of superoxide $\left(\mathrm{O}_{2}^{-}\right)$are described. Cyt-c wired on the mixed self-assembly of DTB and PET displays well-defined voltammetric response at $0.025 \mathrm{~V}$ with a peak-to-peak separation $\left(\Delta E_{p}\right)$ of $5 \mathrm{mV}$. Pyrazine unit in the mixed self-assembly promotes the electron transfer in the redox reaction of surface wired Cyt-c. Cyt-c wired on the mixed self-assembly has been used for the amperometric sensing of superoxide. The enzymatically generated superoxide has been successfully detected using the Cyt-c wired electrode. High sensitivity and fast response for superoxide have been achieved. Uric acid does not interfere in the amperometric measurement of superoxide. The interference due to $\mathrm{H}_{2} \mathrm{O}_{2}$ has been eliminated by using enzyme catalase.
\end{abstract}

Keywords. Mixed self-assembled monolayer; pyrazine; cytochrome c; superoxide sensing; amperometry.

\section{Introduction}

Superoxide $\left(\mathrm{O}_{2}^{-}\right)$is one of the reactive oxygen species produced in vivo, involved in various physiological and pathological procedures. ${ }^{1-3}$ Superoxide is implicated in the pathology of many human diseases. High concentration of superoxide leads to the development of a number of diseases such as cardiovascular dysfunction, ischemia, arteriosclerosis, etc. ${ }^{4-6}$ The precise determination of superoxide is a challenging task, as it is a short-lived radical. The development of fast responding sensing device for the accurate measurement of superoxide is of great interest in analytical chemistry. The determination of superoxide is commonly pursued by electron spin resonance (ESR), ${ }^{7}$ spectrophotometric, ${ }^{8,9}$ micro perfusion, ${ }^{10}$ chemiluminescence, ${ }^{11}$ fluorimetry ${ }^{12}$ and electrochemical ${ }^{13-16}$ methods. The electrochemical methods have several advantages including microfabrication, convenient real time and on-line monitoring. Three different approaches have been used in the electrochemical determination of superoxide: (i) measurement of the concentration of $\mathrm{H}_{2} \mathrm{O}_{2}$ generated during the dismutation of superoxide by superoxide dismutase (SOD), ${ }^{13-15}$ (ii) method based on the electrochemistry of Cyt-c ${ }^{16,17}$ and (iii) using the direct electrochemistry of SOD. ${ }^{18}$ In the first approach, the high potential

*For correspondence required for oxidation of $\mathrm{H}_{2} \mathrm{O}_{2}$ invite interference from other oxidizable species. In the second approach, Cyt-c is reduced by superoxide and the reoxidation of Cyt-c on the electrode surface gives rise to a current proportional to concentration of superoxide. This method of determination has attracted attention in the recent years due to its (i) low working potential for the detection of superoxide, (ii) minimum interference due to other electroactive species and (iii) high sensitivity. Facile electron transfer between the redox protein Cyt-c and electrode surface is very essential for the development of superoxide sensor using this approach.

Cyt-c has been immobilized on monolayer modified electrodes by electrostatic, covalent and specific interactions. ${ }^{19-23}$ Reversible electron transfer for the redox reaction of Cyt-c have been observed on these monolayer modified electrodes. Facile electron transfer for the redox reaction of Cyt-c in homogeneous solution has also been obtained on Au electrode modified with monolayers of different promoters. ${ }^{24-27}$ The interactions that lead to the facilitated electron transfer of Cyt-c on promoter modified electrodes are (i) attractive electrostatic interaction, (ii) hydrogen bonding and (iii) ligation of some functional unit of monolayer with the active site of Cyt-c. Specific functional group present in the promoter interacts with the active site of Cyt-c. The promoter monolayer prevents denaturation of the protein. This interaction of Cyt-c with the promoter 
modified electrode results in immobilization of Cyt$\mathrm{c}$ on the electrode surface. ${ }^{28}$ Yamamoto et al. immobilized Cyt-c on $\omega$-terminated pyridine alkanethiol monolayer containing alkane chain length of more than six methylene units, through the interaction of the pyridine with the heme of the Cyt-c. ${ }^{28}$ Sato and Mizutani utilized the self-assembly of 2-thiouracil and 2-amino6-mercaptopurine to study the electrochemistry of Cytc. ${ }^{29}$ The mixed self-assembly technique has also been utilized to attain a homogeneous monolayer of Cyt-c on the electrode surface. Wei et al. used $\omega$-terminated pyridine or imidazole alkanethiol with a short chain alkanethiol diluent monolayer to immobilize Cyt-c. ${ }^{30}$ The mixed self-assembly allows homogeneous distribution of the redox centre of the protein, hence leads to very fast electron transfer kinetics. ${ }^{30}$ Bowden's group has extensively studied the electrochemistry of Cyt-c with self-assembled monolayer (SAM) of - $\mathrm{COOH}$ terminated long chain alkanethiols and demonstrated the facilitated electron transfer at carboxylic and hydroxyl terminated mixed SAM. ${ }^{31,32}$

Our group is interested in the development of electrochemical sensors for bioanalytes using the self-assemblies of organosulphur compounds and nanomaterials. ${ }^{33-36}$ Recently, we have observed that the self-assembly of heterocyclic thiol promoted electron transfer for the redox reaction of microperoxidase- $11 .^{36}$ In continuation of our research work, here we describe the electrochemistry of Cyt-c immobilized on the mixed self assembly of DTB and PET and the amperometric sensing of superoxide.

\section{Experimental}

\subsection{Chemicals}

DTB, 1-ethyl-3-(3-dimethylaminopropyl)carbodiimide (EDC), uric acid (UA), xanthine, xanthine oxidase (XOD) (EC 1.1.3.22) from butter milk, SOD (EC 1.15.1.1) from bovine erythrocytes, Cyt-c from horse heart and catalase (EC 1.11.1.6) from bovine liver were obtained from Sigma-Aldrich and used as received. PET was obtained from Alfa Aesar. Hydrogen peroxide (30\% solution) was obtained from Merck, Germany. Deionized water (Milli Q System) was used for the preparation of all the solutions Sodium phosphate buffer solution (PBS) $(5 \mathrm{mM})$ of $\mathrm{pH} 7.2$ was used as supporting electrolyte in all the cyclic voltammetric and amperometric measurements.

\subsection{Instrumentation}

All the electrochemical measurements were performed with CHI643B electrochemical analyzer (CH Instruments, Austin, TX) attached with a Faraday cage/ current booster. A two-compartment three-electrode cell with a polycrystalline $\mathrm{Au}$ working electrode ( $1.6 \mathrm{~mm}$ diameter), a platinum wire auxiliary electrode and $\mathrm{Ag} / \mathrm{AgCl}$ reference electrode $(3 \mathrm{M} \mathrm{KCl})$ was used in the measurements. All the results described here were carried out at least three times and reproducible results were obtained in all the cases. Electrochemical impedance spectroscopic (ESI) measurements were performed with Autolab potentiostat-galvanostat $(302 \mathrm{~N})$ in $0.1 \mathrm{M}$ PBS (pH 7.2) containing $1 \mathrm{mM}$ $\left[\mathrm{Fe}(\mathrm{CN})_{6}\right]^{3-/ 4-}$ as a redox probe. The impedance at the formal potential of the redox probe, which was superimposed on $5 \mathrm{mV}$ rms sinusoidal potential modulations, was measured in the frequency range of $1 \times 10^{-2}-5 \times$ $10^{5} \mathrm{~Hz}$

\subsection{Preparation of SAMs}

Polycrystalline $\mathrm{Au}$ electrodes were polished repeatedly with alumina powder $(0.06 \mu \mathrm{m})$ and sonicated in water for 5-10 $\mathrm{min}$. The polished electrodes were then electrochemically pretreated by cycling the potential between -0.2 and $1.5 \mathrm{~V}$ at the scan rate of $10 \mathrm{~V} / \mathrm{s}$ in $0.25 \mathrm{M} \mathrm{H}_{2} \mathrm{SO}_{4}$ until the characteristic cyclic voltammogram for a clean Au electrode was obtained. The pre-treated electrodes were then soaked in ethanolic solution of DTB $(1 \mathrm{mM})$ or PET $(0.25 \mathrm{mM})$ for a period of $2 \mathrm{~h}$ at room temperature for the formation of SAM. Mixed self-assemblies of DTB and PET were made by immersing the cleaned Au electrode in ethanol solutions containing different molar ratios of DTB and PET (DTB: PET is $1: 1,1: 0.5,1: 0.25$ ) for $2 \mathrm{~h}$. These SAM modified electrodes were rinsed extensively with ethanol and water and subjected to further modification. These SAM modified electrodes will be referred as DTB, PET and DTB-PET electrodes.

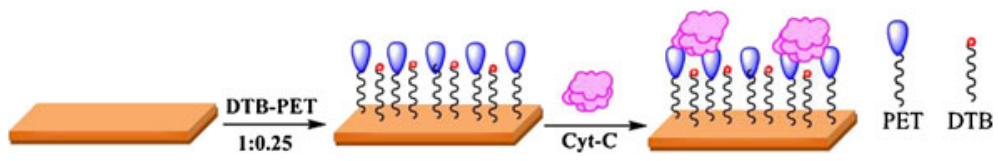

Scheme 1. Scheme illustrating the covalent immobilization of Cyt-c on DTB-PET electrode. 
Cyt-c has been immobilized on SAM modified electrode surface via electrostatic interaction and covalent coupling (scheme 1). Immobilization of Cyt-c via electrostatic interaction was achieved by soaking the SAM modified electrode in PBS containing Cyt-c $(50 \mu \mathrm{M})$ for $3 \mathrm{~h}$. The positively charged lysine residues of Cyt$\mathrm{c}$ favour the immobilization on the negatively charged SAM. For covalent coupling of Cyt-c, the DTB and DTB-PET electrodes were incubated in $50 \mu \mathrm{M}$ Cytc in $5 \mathrm{mM}$ PBS of pH 7.2 containing EDC $(2.5 \mathrm{mM})$ for $3 \mathrm{~h}$ at $4^{\circ} \mathrm{C}$. The Cyt-c immobilized electrodes were then rinsed with PBS and subjected to electrochemical experiments. The amperometric sensing of superoxide was carried out at the potential of $0.15 \mathrm{~V}$. Xanthine oxidase $(35 \mathrm{mU} / \mathrm{ml})$ was added to an oxygen saturated PBS containing xanthine $(1 \mathrm{mM})$ to generate superoxide. Catalase was added to the solution to minimize interference due to enzymatically generated $\mathrm{H}_{2} \mathrm{O}_{2}$.

\section{Results and discussion}

\subsection{Electrochemical characterization of self-assembled monolayers}

The self-assemblies of DTB and DTB-PET were electrochemically characterized by determining the interfacial capacitance, surface coverage and voltammetric response towards hydrophilic redox probe $\mathrm{Fe}(\mathrm{CN})_{6}^{3-/ 4-}$. The capacitance and surface coverage measurement can provide a qualitative understanding on the nature of the monolayer. The capacitances of the monolayer modified electrodes were measured at $0.05 \mathrm{~V}$ in neutral $\mathrm{pH}$ taking the charging current into account. ${ }^{37}$ The capacitance values of DTB, PET and DTB-PET (1:0.25) electrodes are $14 \pm 1,8 \pm 1.5$ and $18 \pm 2 \mu \mathrm{F} / \mathrm{cm}^{2}$, respectively. It is generally known that the capacitance of monolayer depends on the packing density, quality and the nature of the functional groups of the monolayer. The high capacitance values for the DTB and DTB-PET monolayers suggest the easy permeation of electrolyte ions into the SAM. It is well-documented in the literature that the terminal group has strong influence on the capacitance of SAM modified electrodes and the $-\mathrm{COOH}$ terminated monolayers are more permeable to the electrolyte ions than the other monolayer. ${ }^{38}$ The nature and the packing density of the SAM modified electrodes were further understood by measuring the surface coverage $(\Gamma)$ of the self-assembly. The $\Gamma$ was calculated by measuring the charge consumed during the reductive desorption of the respective monolayer assembly from the electrode surface in $0.1 \mathrm{M} \mathrm{KOH}$. The $\Gamma$ of DTB, PET and DTB-PET electrodes are $4.8 \pm$
$0.4,6.5 \pm 0.2$ and $2.8 \pm 0.25 \times 10^{-10} \mathrm{~mol} / \mathrm{cm}^{2}$, respectively. The low $\Gamma$ of DTB-PET electrode suggests the less compact nature of the monolayer.

The electrochemical behaviour of DTB, PET and DTB-PET electrodes towards $\mathrm{Fe}(\mathrm{CN})_{6}^{3-/ 4-}$ was studied in neutral $\mathrm{pH}$ (figure $\mathrm{S} 1$ ). The DTB and DTB-PET electrodes show sluggish voltammetric response towards $\mathrm{Fe}(\mathrm{CN})_{6}^{3-/ 4-}$. The $\Delta E_{\mathrm{p}}$ value is significantly large and the peak current is low on the DTB and DTB-PET electrodes. The charge transfer kinetics of the monolayers was further studied by EIS using $\left.\mathrm{Fe}(\mathrm{CN})_{6}\right]^{3-/ 4-}$ as redox probe (figure $\mathrm{S} 1 \mathrm{~B}$ ). The charge transfer resistance $R_{\mathrm{ct}}$ values were calculated by fitting the data using Randles equivalent circuit. The $R_{\mathrm{ct}}$ value at the DTB $(340 \mathrm{k} \Omega)$ and DTB-PET $(245 \mathrm{k} \Omega)$ monolayer-modified electrodes is significantly higher than those of the bare $(3.84 \mathrm{k} \Omega)$ and PET $(24.7 \mathrm{k} \Omega)$ electrodes. The $R_{\mathrm{ct}}$ and $\Delta E_{\mathrm{p}}$ value obtained at PET electrode implies that the monolayer does not impede the permeation of redox probe towards electrode surface. The PET has two $\mathrm{p} K_{\mathrm{a}}$ $(0.6 \text { and } 1.1)^{39,40}$ in aqueous solution and the monolayer assembly is expected to be neutral in the experimental conditions used in this investigation. On the other hand, the DTB monolayer contains terminal $-\mathrm{COOH}$ groups which are expected to be deprotonated at neutral $\mathrm{pH}$. The electrostatic effect controls the charge transfer kinetics at the DTB and DTB-PET monolayer assemblies. It has been observed that the acid-base behaviour of a surface confined molecule is different from that of the corresponding molecule in solution. The acidity of the surface confined molecule largely depends on the local environment especially on the surface polarity and electrostatic field of the interface. ${ }^{41,42}$ Hence the surface $\mathrm{p} K_{a}$ of $-\mathrm{COOH}$ terminated alkane thiols and disulphides is usually observed to be 3-4 units higher than the $\mathrm{p} K_{a}$ in solution, ${ }^{41,42}$ The surface $\mathrm{p} K_{\mathrm{a}}$ of DTB in the single and mixed self-assemblies were determined by voltammetric titration in solution of different $\mathrm{pH}$ using the redox probe $\mathrm{Fe}(\mathrm{CN})_{6}^{3-/ 4-}$. The $\Delta E_{p}$ for the redox reaction of $\mathrm{Fe}(\mathrm{CN})_{6}^{3-/ 4-}$ was measured at different $\mathrm{pH}$ (figure 1). From the titration curve, the surface $\mathrm{p} K_{a}$ was calculated to be 5.9 for DTB which is 1.5 units higher than the solution $\mathrm{p} K_{a}\left(\mathrm{p} K_{a}^{\mathrm{DTB}} 4.5\right)$. The surface $\mathrm{p} K_{a}$ of DTB in the mixed self-assembly was calculated to be 6.6 and this value is higher than that observed in the single self-assembly (figure 1). The increase in the surface $\mathrm{p} K_{a}$ of DTB can be explained by considering the change in the hydrophobicity ${ }^{43,44}$ of the self-assembly: The introduction of PET into the self-assembly of DTB increases the surface $\mathrm{p} K_{a}$ by 0.7 , presumably due to the increase in the hydrophobicity of the monolayer. The sluggish electron transfer kinetics observed for the redox probe at neutral $\mathrm{pH}$ on 

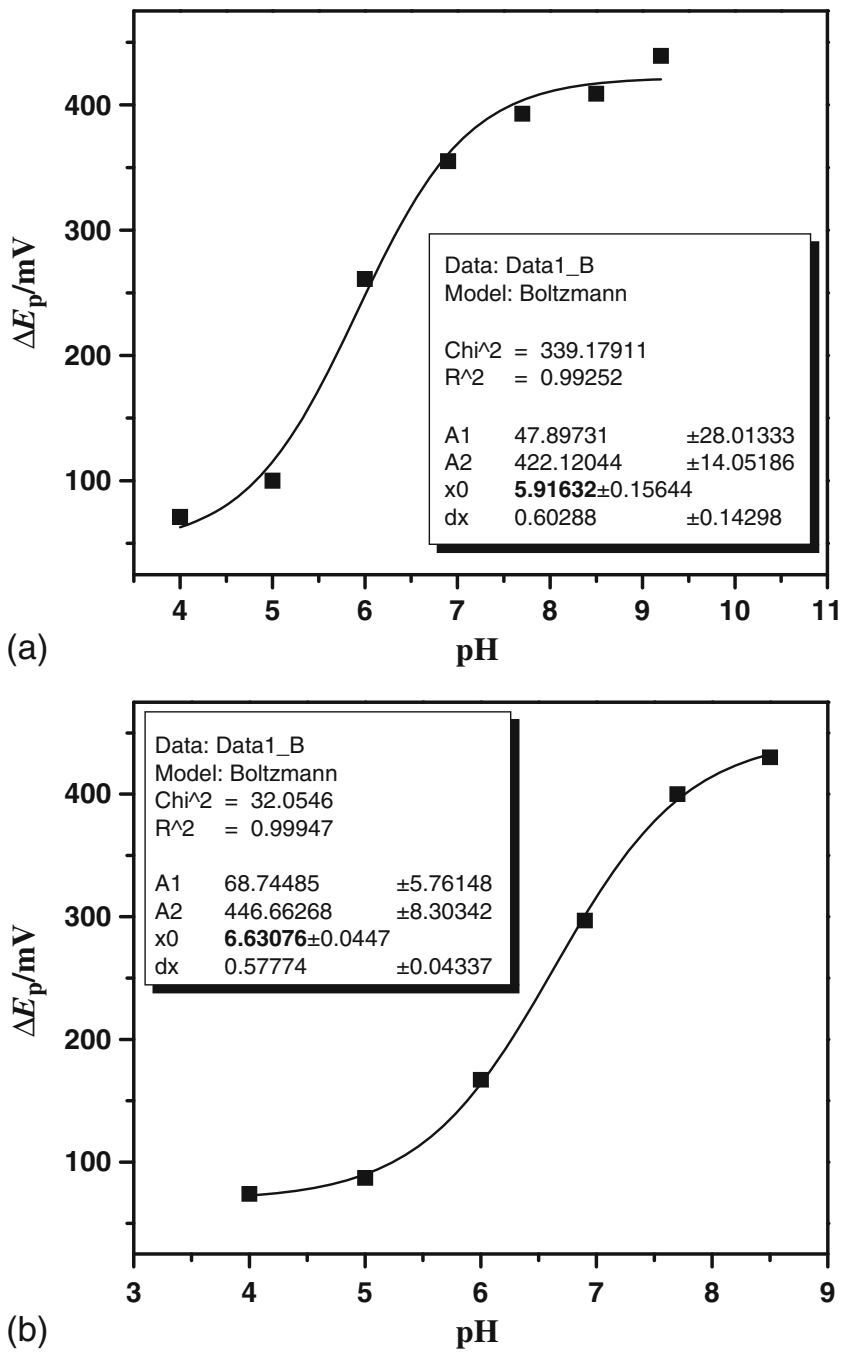

Figure 1. Voltammetric titration curve for the determination of surface $\mathrm{p} K_{\mathrm{a}}$ of DTB in the (a) single and (b) mixed self-assemblies. The $\Delta E_{\mathrm{p}}$ value obtained for the redox response of $\left[\mathrm{Fe}(\mathrm{CN})_{6}\right]^{3-/ 4-}$ couple on the single and mixed self-assemblies are plotted against solution $\mathrm{pH}$.

the DTB and DTB-PET electrode is due to the electrostatic repulsion of $\mathrm{Fe}(\mathrm{CN})_{6}^{3-/ 4-}$ with the monolayer assembly. In the impedance measurements, the large $R_{\mathrm{ct}}$ value obtained on the DTB monolayer is ascribed to the electrostatic repulsion of $\mathrm{Fe}(\mathrm{CN})_{6}^{3-/ 4-}$ with the negatively charged monolayer assembly. On the other hand, the $R_{\mathrm{ct}}$ on the PET suggest that the monolayer assembly does not impede the electron transfer event. In the case of DTB-PET mixed self-assembly, the $R_{\mathrm{ct}}$ value is significantly higher than the PET and is less than the DTB monolayer, implying that the $\mathrm{Fe}(\mathrm{CN})_{6}^{3-/ 4-}$ experiences electrostatic repulsion, though not as in the case of DTB. The negatively charged DTB in the mixed self-assembly does not favour the permeation of the redox molecules to the electrode surface. The electron transfer kinetics on the mixed monolayer assembly is largely dependent on the molar ratio of DTB and PET.

\subsection{Electrochemistry of Cyt-c}

Figure $2 \mathrm{a}$ shows the voltammograms obtained for covalently immobilized Cyt-c on DTB and DTB-PET (1:0.25 molar ratio) electrodes. Reversible voltammetric response with formal potential $\left(E^{\circ \prime}\right)$ of $0.025 \mathrm{~V}$ was observed on both the electrodes. Close examination of the voltammetric profile reveals the following: (i) The $\Delta E_{\mathrm{p}}$ value on both DTB and DTB-PET electrode is very small $(5 \mathrm{mV})$. (ii) The peak width at half height $\left(E_{\mathrm{pwh}}\right)$ is relatively small in the case of DTB-PET electrode $(100 \mathrm{mV})$. The voltammetric response on DTB electrode is rather broad $\left(E_{\mathrm{pwh}}=\right.$ $120 \mathrm{mV}$ ). (iii) The $\Gamma$ of Cyt-c was obtained by integrating the area under the cathodic or anodic peak and the $\Gamma$ on DTB-PET electrode was higher $(6 \pm 0.5 \times$ $\left.10^{-12} \mathrm{~mol} \mathrm{~cm}^{-2}\right)$ than that on the DTB electrode (4.5 $\pm 0.3 \times 10^{-12} \mathrm{~mol} \mathrm{~cm}^{-2}$ ). (iv) The voltammetric peak current linearly increases with scan rate on both electrodes, indicating that the response corresponds to a surface confined redox species (figure 2b). On DTB-PET electrode, the voltammetric response is well-defined, indicating the facile electron transfer kinetics. The heterogeneous electron transfer rate constant $\left(k_{\mathrm{s}}^{a p p}\right)$ for Cyt-c at DTB and DTB-PET electrodes was calculated by Laviron's approach ${ }^{45}$ from the variation of peak potential with scan rate. The $\Delta E_{\mathrm{p}}$ value was less than $200 / \mathrm{n} \mathrm{mV}$ at high scan rate and the transfer coefficient $\alpha$ was obtained from the working curve. The $k_{\mathrm{s}}^{a p p}$ value for the redox reaction of Cyt-c on the DTB and DTB-PET electrode was calculated to be $88 \pm 0.5 \mathrm{~s}^{-1}$ and $99 \pm 1 \mathrm{~s}^{-1}$, respectively. The $k_{\mathrm{s}}^{a p p}$ value obtained for Cyt-c on these electrodes is quite high in comparison to the reported values of $k_{\mathrm{s}}^{a p p}$ at other $-\mathrm{COOH}$ terminated aliphatic thiols. ${ }^{16,17,31}$ Collinson and Bowden observed $k_{s}^{a p p}$ of $1 \mathrm{~s}^{-1}$ for Cyt-c covalently immobilized on 16-mercaptohexadecanoic acid SAM modified electrode. ${ }^{31} \mathrm{Ge}$ and Lisdat obtained $k_{s}^{a p p}$ of $3-5 \mathrm{~s}^{-1}$ for Cyt-c covalently immobilized on the self-assembly of 11-mercaptoundecanoic acid. ${ }^{17}$ Kasmi et al. obtained $k_{s}^{a p p}$ of $18 \mathrm{~s}^{-1}$ on a 7-mercaptoheptanoic acid SAMmodified electrode. ${ }^{32}$ Finklea and Hanshew have suggested that with increase in the chain length of self-assembly, the electron transfer rate decreases. ${ }^{46}$ On DTB electrode we observed $k_{s}^{a p p}$ value of $88 \mathrm{~s}^{-1}$ for covalently immobilized Cyt-c whereas the mixed selfassembly yields a value of $99 \mathrm{~s}^{-1}$. Enhancement in the $k_{s}^{a p p}$ value on the mixed self-assembly of DTB and PET can be ascribed to the promoted electron transfer by the pyrazine unit in the mixed self-assembly. 

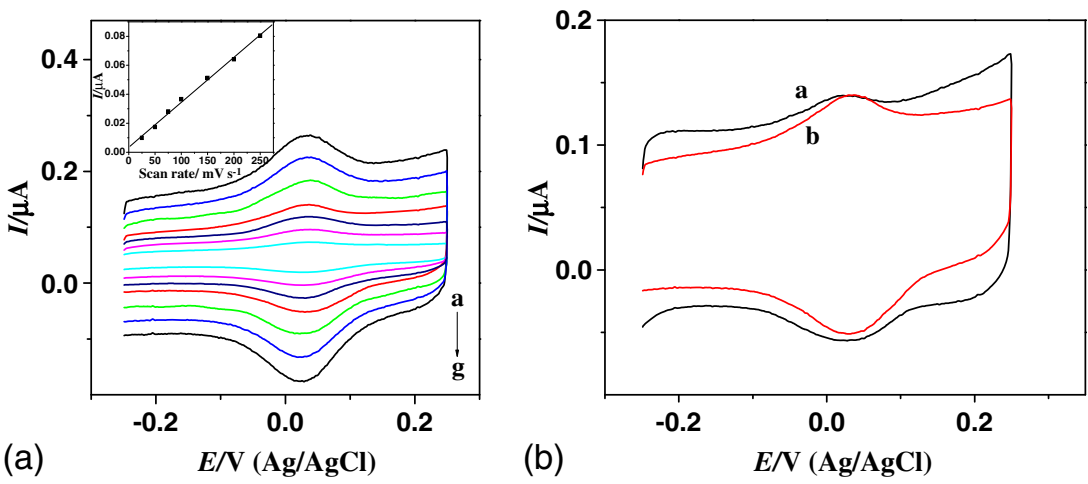

Figure 2. (a) Cyclic voltammograms obtained for covalently bound Cyt-c on DTB-PET electrode at different scan rate (a) 25, (b) 50, (c) 75, (d) 100, (e) 150 , (f) 200, (g) $250 \mathrm{mV} / \mathrm{s}$. Inset shows the plot of anodic peak current against scan rate. (b) Cyclic voltammograms obtained for covalently bound Cyt-c on (a) DTB and (b) DTB-PET electrodes in $5 \mathrm{mM}$ PBS. Scan rate: $100 \mathrm{mV} / \mathrm{s}$.

Figure 3 represents the voltammetric profile obtained for the electrostatically immobilized Cyt-c on DTB and DTB-PET electrodes. Reversible voltammetric response with $E^{\circ}$ of 0 and $0.01 \mathrm{~V}$ was observed for DTB and DTB-PET electrodes, respectively. The $\Delta E_{\mathrm{p}}$ value on the DTB-PET electrode is significantly lower than that on the DTB electrode. The $\Gamma$ of Cyt-c on the DTB and DTB-PET electrode was calculated to be $3 \pm$ $0.2 \times 10^{-12}$ and $4.2 \pm 0.5 \times 10^{-12} \mathrm{~mol} \mathrm{~cm}^{-2}$, respectively. The $\Gamma$ value is relatively high in the case of DTBPET electrode. The DTB-PET electrode shows facile electron transfer for the redox reaction of Cyt-c immobilized by covalent as well as electrostatic procedures, indicating that the PET monolayer has a key role in promoting the electron transfer. To further understand

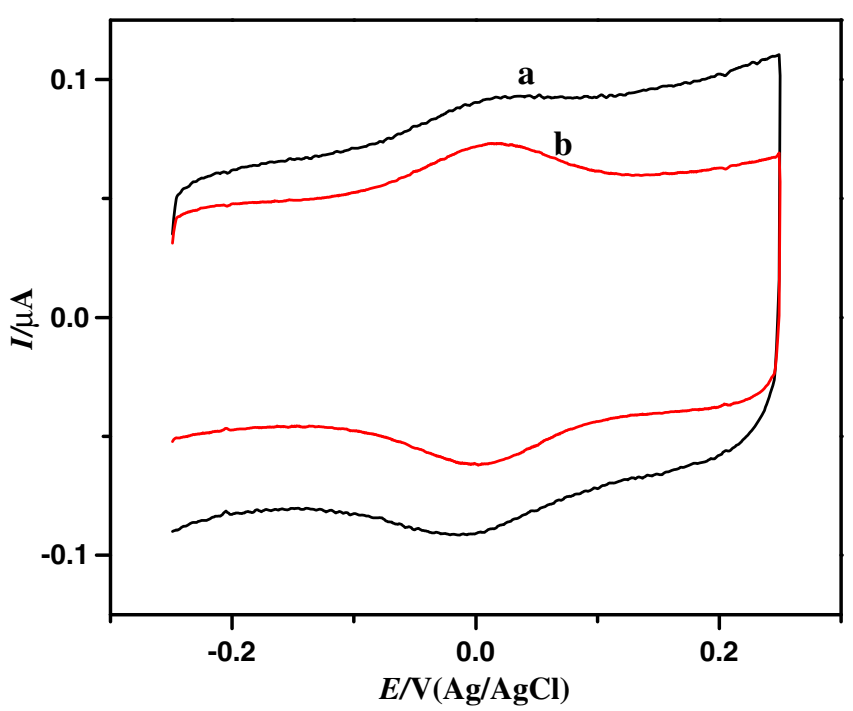

Figure 3. Cyclic voltammograms obtained for electrostatically bound Cyt-c on (a) DTB and (b) DTB-PET electrodes. Scan rate: $100 \mathrm{mV} / \mathrm{s}$. the role of the self-assembly of PET, the electrochemistry of Cyt-c was investigated on mixed self-assembly at different molar ratio of PET (DTB:PET; 1:1 and 1:0.5). As shown in table 1 gradual positive shift in the $E^{\circ \prime}$ and decrease in the $\Gamma$ have been noticed while increasing the ratio of PET on the electrode surface. The electrode modified with the single monolayer assembly of PET does not show any characteristic voltammogram for Cyt-c. The mixed self-assembly with 1: 0.25 (DTB:PET) ratio exhibits well-defined voltammogram with high $\Gamma$.

It is well-recognized that the nitrogen containing heterocycles such as purine and pyridine promote the redox reaction of Cyt-c in solution. ${ }^{24,25,47-49}$ It has been shown that Cyt-c can be immobilized on pyridine, purine, and nitrile terminated SAMs via specific binding of heme unit of Cyt-c with nitrogen atom. ${ }^{28,30,50}$ The nitrogen atom directly associates with redox unit of Cyt-c and create a better defined geometry between redox protein and the electrode surface. ${ }^{28}$ Large shift in the $E^{\circ \prime}$ of surface confined Cyt-c has been observed on the SAMs of these heterocyclic thiol modified electrodes. In our case, although the $E^{\circ \prime}$ value has not shifted, promoted electron transfer has been observed. The $E^{\circ \prime}$ value observed on the DTB-PET electrode is very close to those observed for Cyt-c in homogeneous solution on a pyridine functionalized electrode. ${ }^{24}$ The facile electron transfer on the DTB-PET electrode can be attributed to the favourable interaction of Cyt-c with pyrazine unit of the self-assembly.

\subsection{Sensing of superoxide}

DTB-PET electrode facilitates the electron transfer for the redox reaction of Cyt-c and therefore it can be used as a versatile platform for the sensing of superoxide. 
Table 1. Voltammetric data obtained for Cyt-c immobilized on SAM modified electrodes.

\begin{tabular}{llccccc}
\hline Cyt-c & Electrode & $E^{\prime \prime} / \mathrm{V}$ & $\Delta E_{\mathrm{p}}^{*} / \mathrm{mV}$ & $E_{\mathrm{pwh}} / \mathrm{mV}$ & $k_{\mathrm{s}}^{a p p} / \mathrm{s}^{-1}$ & $\Gamma / 10^{-12} \mathrm{~mol} \mathrm{~cm}^{-2}$ \\
\hline Covalent binding & DTB & 0.025 & 5 & 120 & $88 \pm 0.5$ & $4.5 \pm 0.3$ \\
& DTB-PET (1:0.25) & 0.025 & 2 & 100 & $99 \pm 1$ & $6 \pm 0.5$ \\
& DTB-PET (1:0.5) & 0.04 & 5 & 96 & $99 \pm 1$ & $4 \pm 0.5$ \\
\multirow{5}{*}{ Non covalent binding } & DTB-PET (1:1) & 0.045 & 5 & 90 & $99 \pm 1$ & $2.4 \pm 0.2$ \\
& DTB & 0 & 30 & 105 & $54 \pm 0.6$ & $3 \pm 0.2$ \\
& DTB-PET (1:0.25) & 0.01 & 10 & 90 & $84 \pm 1$ & $4.2 \pm 0.5$ \\
& DTB-PET (1:0.5) & 0.015 & 18 & 95 & $84 \pm 1$ & $4 \pm 0.2$ \\
& DTB-PET (1:1) & $\sim 0.025$ & 50 & - & - & $0.7 \pm 0.1$ \\
\hline
\end{tabular}

*Obtained at $100 \mathrm{mV} / \mathrm{s}$.

The sensing methodology involves the enzymatic generation of superoxide and its detection by Cytc immobilized DTB-PET electrode according to Eqs 1-4.

$$
\text { Xanthine }+2 \mathrm{O}_{2} \stackrel{\text { XOD }}{\longrightarrow} \text { Uric acid }+\mathrm{O}_{2}^{-}+\mathrm{H}_{2} \mathrm{O}_{2} \text {. }
$$

$$
\begin{aligned}
2 \mathrm{O}_{2}^{-}+2 \mathrm{H}^{+} & \longrightarrow \mathrm{O}_{2}+\mathrm{H}_{2} \mathrm{O}_{2} . \\
\mathrm{O}_{2}^{-}+\mathrm{Cytc}\left(\mathrm{Fe}^{3+}\right) & \longrightarrow \mathrm{O}_{2}+\mathrm{Cytc}\left(\mathrm{Fe}^{2+}\right) . \\
\mathrm{Cytc}\left(\mathrm{Fe}^{2+}\right) & \longrightarrow \mathrm{Cytc}\left(\mathrm{Fe}^{3+}\right)+\mathrm{e}^{-} .
\end{aligned}
$$

The enzymatically generated superoxide can undergo spontaneous dismutation to oxygen and hydrogen peroxide (Eq. 2). Under optimized reaction conditions, the counterbalance between the superoxide generation and dismutation results in steady state concentration of superoxide in solution. Enzymatically generated superoxide reduces the surface confined Cyt-c (Eq. 3). The reduced form of Cyt-c is oxidized on the electrode surface at $0.15 \mathrm{~V}$ (Eq. 4). The schematic representation of superoxide sensor is shown in scheme 2. The cyclic voltammogram recorded in the presence of superoxide shows an increase in the anodic peak current with decrease in the cathodic peak current, indicating that the superoxide is electrocatalytically oxidized by the surface confined Cyt-c (figure S2).

The amperometric response of Cyt-c covalently immobilized on DTB-PET electrode for enzymatically generated superoxide is shown in figure 4. Large anodic current corresponding to the oxidation of surface confined Cyt-c was observed upon the addition of XOD to the solution containing xanthine and oxygen. The response time was $14 \mathrm{~s}$. Addition of SOD, a scavenger of superoxide resulted in a sudden decrease (84\% of the initial current) in the amperometric current, demonstrating that the anodic current obtained upon the addition of XOD corresponds to the oxidation of Cyt-c (Eq. 4). Figure 5 is the calibration plot obtained for the sensing of superoxide. Under steady state condition, the concentration of $\mathrm{O}_{2}^{-}$is proportional to the square root of XOD activity. ${ }^{51}$ Linear response was obtained up to $150 \mathrm{mU} \mathrm{ml}^{-1}$ of XOD. The sensitivity of the electrode towards superoxide has been obtained from the calibration plot and was $3.45 \pm 0.06 \mathrm{nA} \mathrm{cm}^{-2}\left[\mathrm{XOD}^{-1 / 2}\right.$. It should be mentioned here that the lack of long term stability of the biosensors based on self-assembled monolayers is a serious concern, ${ }^{52}$ despite the fact that they have very good sensitivity, response time, etc. In the present case, the superoxide biosensors can be used as a disposable sensing platform.

The interference due to the $\mathrm{H}_{2} \mathrm{O}_{2}$ and UA generated during the enzymatic reaction is a concern in the amperometric detection of $\mathrm{O}_{2}^{-}$. To examine the possible interference due to these analytes, amperometric measurements have been performed with the Cyt-c electrode. To eliminate the interference due to $\mathrm{H}_{2} \mathrm{O}_{2}$, catalase enzyme has been taken in solution which

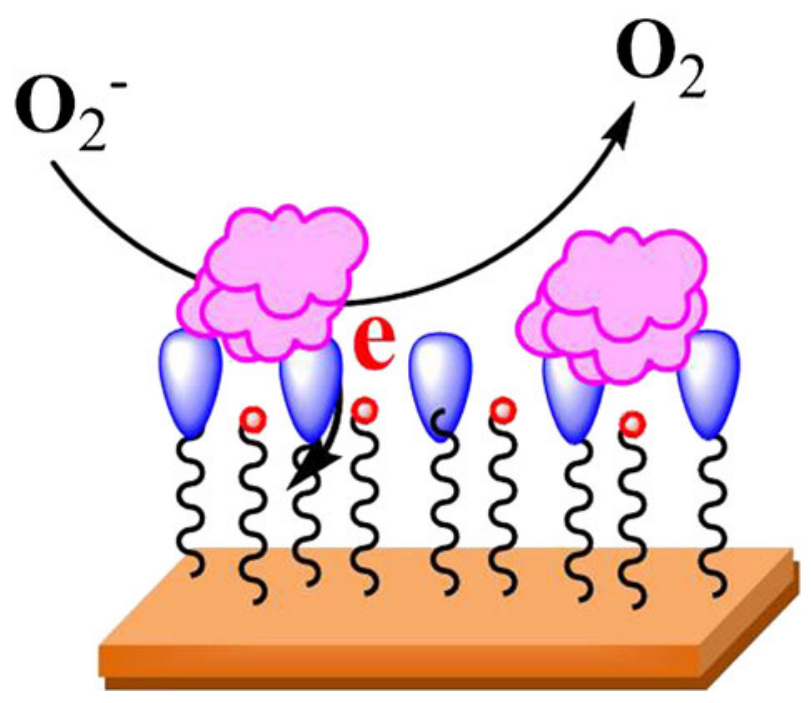

Scheme 2. Schematic representation of the superoxide sensor. 


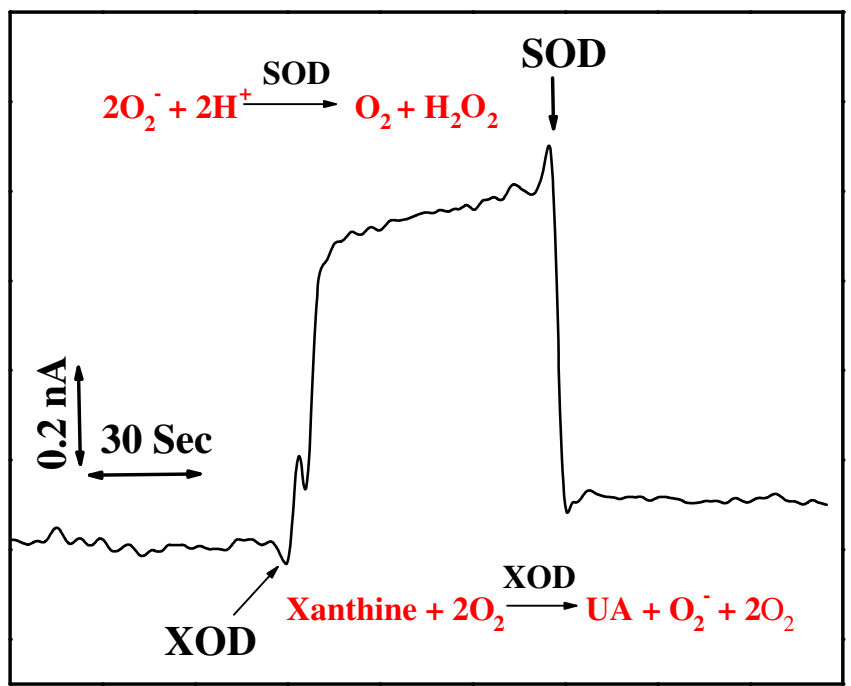

Figure 4. Amperometric response of the superoxide sensor during the generation and dismutation of superoxide in $5 \mathrm{mM}$ PBS (air saturated). [XOD] $=35 \mathrm{mU} \mathrm{ml}^{-1}$, [SOD] $=$ $11 \mathrm{U} \mathrm{ml}^{-1}$, [xanthine $]=1 \mathrm{mM}$.

specifically decomposes $\mathrm{H}_{2} \mathrm{O}_{2} \cdot \mathrm{H}_{2} \mathrm{O}_{2}$ does not interfere in the measurement of superoxide in the presence of catalase (figure S3). Moreover, the enzymatically generated UA does not interfere in the amperometric measurement of superoxide at such low working potential of $+0.15 \mathrm{~V}$ (figure S3).

It is worth comparing the performance of the Cytc modified electrode towards superoxide with the existing reports. Lisdat et al. utilized Cyt-c immobilized on 11-mercaptoundecanoic acid SAM modified electrode for the sensing of superoxide. ${ }^{53}$ They

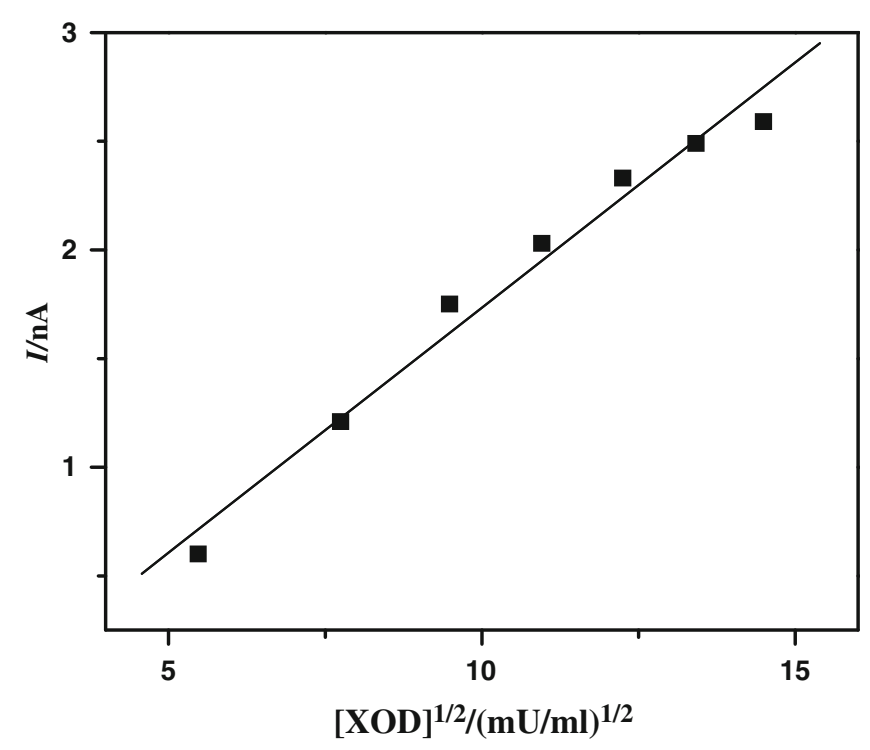

Figure 5. Calibration plot for the sensing of superoxide. Amperometric current obtained for oxidation of superoxide is plotted against the square root of XOD activity. obtained a sensitivity of $9 \mathrm{nA} \mathrm{cm}{ }^{-2}[\mathrm{XOD}]^{-1 / 2}$ towards superoxide. Linear response towards superoxide was obtained up to $100 \mathrm{mU} \mathrm{ml}^{-1}$ of XOD. Ge and Lisdat reported sensing of superoxide on Cyt-c immobilized on the mixed self-assembly of 11-mercaptoundecanoic acid and 11-mercaptoundecanol. ${ }^{17}$ Linear amperometric response was obtained up to $50 \mathrm{mU} \mathrm{ml}^{-1}$ of XOD. Gobi and Mizutani reported sensing of superoxide on a Cyt-c immobilized on mixed self-assembly of 3-mercaptopropionic acid and 3-mercaptopropanol. ${ }^{54}$ They obtained amperometric current, $3 \pm 0.2 \mathrm{nA}$ for addition of $60 \mathrm{mU} \mathrm{ml}^{-1}$ of XOD with a response time of $15 \mathrm{~s}$. On comparing the results with reported literature it was observed that the present Cyt-c modified electrode shows linear response for superoxide in a more wide concentration range, up to $150 \mathrm{mU} \mathrm{ml}^{-1}$ of $\mathrm{XOD}$ and the potential interferents $\mathrm{H}_{2} \mathrm{O}_{2}$ and UA do not interfere in the amperometric measurement.

\section{Conclusions}

The electrochemical characteristics of Cyt-c wired on the electrode modified with the self-assemblies of DTB and DTB-PET have been studied. Facile electron transfer reaction has been observed on the mixed selfassembly of DTB and PET. The pyrazine unit of the self-assembly promotes the electron transfer for the redox reaction of Cyt-c on the electrode surface. The apparent heterogeneous electron transfer rate constant for the redox reaction on the mixed self-assembly is relatively high with respect to the single monolayer assembly of DTB. The amperometric sensing of superoxide has been achieved using the Cyt-c immobilized mixed self-assembly at the potential of $+0.15 \mathrm{~V}$. High sensitivity and fast response for superoxide have been observed.

\section{Supplementary material}

Figures S1-S3 are given as supplementary materials. The electronic supplementary information can be seen in www.ias.ac.in/chemsci website.

\section{Acknowledgements}

This work was financially supported by the Department of Science and Technology (DST) and Council of Scientific and Industrial Research (CSIR), New Delhi.

\section{References}

1. Fabian R H and Kent T A 1999 Free Rad. Biol. Med. 26 355 
2. Kozniewska E, Reszka R and Lisdat F 1999 J. Cerebral Blood Flow Metab. 19740

3. Hancock J T 1997 Br. J. Biomed. Sci. 5438

4. Heurtaux T, Benani A, Bianchi A, Moindrot A, Gradinaru D, Magdalou J, Netter P and Minn A 2004 Free Radical Biol. Med. 371051

5. Lebel C P and Bondy S C 1991 Neurotoxicol. Teratol. 13341

6. Olanow C W 1993 Trends Neurosci. 16439

7. Tarpey M M and Fridovich I 2001 Circ. Res. 89224

8. Mills G, Schmidt K H, Matheson M S and Meisel D 1987 J. Phys. Chem. 911590

9. McCord J M and Fridovich I 1969 J. Biol. Chem. 244 6049

10. Lisdat F and Scheller F W 2000 Anal. Lett. 331

11. Yao D, Vlessidis A G, Evmiridis N P, Zhou Y, Xu S and Zhou H 2002 Anal. Chim. Act. 467145

12. Ohyashiki T, Nunomura M and Katoh T 1999 Biochim. Biophys. Act. 1421131

13. Mesaros S, Vankova Z, Grunfeld S, Mesarosova A and Malinski T 1998 Anal. Chim. Act. 35827

14. Lvovich V and Scheeline A 1997 Anal. Chem. 69454

15. Song M I, Bier F F and Scheller F W 1995 Bioelectrochem. Bioenerg. 38419

16. Beissenhirtz M K, Scheller F W and Lisdat F 2004 Anal. Chem. 764665

17. Ge B and Lisdat F 2002 Anal. Chim. Act. 45453

18. Tian Y, Mao L, Okajima T and Ohsaka T 2004 Anal. Chem. 764162

19. Tarlov M J and Bowden E F 1991 J. Am. Chem. Soc. 113 1847

20. Nahir T M, Clark R A and Bowden E F 1994 Anal. Chem. 662595

21. Clark R A and Bowden E F 1997 Langmuir 13559

22. Feng Z Q, Imabayashi S, Kakiuchi T and Niki K 1995 J. Electroanal. Chem. 394149

23. Niki K, Hardy W R, Hill M G, Li H, Sprinkle J R, Margoliash E, Fujita K, Tanimura R, Nakamura N, Ohno H, Richards J H and Gray H B 2003 J. Phys. Chem. 107B 9947

24. Taniguchi I, Toyosawa K, Yamaguchi H and Yasukouchi K 1982 J. Electroanal. Chem. 140187

25. Taniguchi I, Yoshimoto S, Yoshida M, Kobayashi S-I, Miyawaki T, Aono Y, Sunatsuki Y and Taira H 2000 Electrochim. Act. 452843

26. Huang Z X, Feng M, Wang Y-H, Cui J and Zou D-S 1996 J. Electroanal. Chem. 41631

27. Armstrong F A, Hill H A O and Walton N J 1988 Acc. Chem. Res. 21407
28. Yamamoto H, Liu H and Waldeck D H 2001 Chem. Commun. 111032

29. Sato Y and Mizutani F 2000 Electrochim. Act. 452869

30. Wei J, Liu H, Dick A R, Yamamoto H, He Y and Waldeck D H 2002 J. Am. Chem. Soc. 1249591

31. Collinson M and Bowden E F 1992 Langmuir 81247

32. Kasmi A E, Wallace J M, Bowden E F, Binet S M and Linderman R J 1998 J. Am. Chem. Soc. 120225

33. Dey R S and Raj C R 2012 Chem. Asian J. 7417

34. Dey R S, Gupta S, Paira R and Raj C R 2010 ACS Appl. Mater. Interfaces 21355

35. Jena B K and Raj C R 2006 Anal. Chem. 786332

36. Behera S and Raj C R 2007 Biosens. Bioelectron. 23556

37. Bard A J and Faulkner L R 2000 Electrochemical Methods-Fundamentals and Applications (New York: John Wiley and Sons) pp. 12

38. Finklea H O 1996 In: A J Bard and I Rubinstein (eds.) Electroanalytical chemistry, volume 19 (NY: Marcel Dekker)

39. Albert A and Phillips J N 1956 J. Chem. Soc. 1294

40. Keyworth D A 1959 J. Org. Chem. 241355

41. White H S, Peterson J D, Cui Q and Stevenson K J 1998 J. Phys. Chem. 102B 2930

42. Kakiuchi T, Iida M, Imabayashi S-I and Niki K 2000 Langmuir 165397

43. Kim K and Kwak J 2001 J. Electroanal. Chem. 51283

44. Raj C R and Behera S 2005 J. Electroanal. Chem. 581 61

45. Laviron E 1979 J. Electroanal. Chem. 10119

46. Finklea H O and Hanshew D D 1992 J. Am. Chem. Soc. 1143173

47. Eddowes M J, Hill H A O and Uosaki K $1979 \mathrm{~J}$. Am. Chem. Soc. 1017113

48. Taniguchi I, Higo N, Umekita K and Yasukouchi K 1986 J. Electroanal. Chem. 206341

49. Taniguchi I, Ishimoto H, Miyagawa K, Iwai M, Nagai H, Hanazono H, Taira K, Kubo A, Nishikawa A, Nishiyama K, Dursun Z, Hareau G P-J and Tazaki M 2003 Electrochem. Commun. 5857

50. Murgida D H, Hildebrandt P, Wei J, He Y-F, Liu H and Waldeck D H 2004 J. Phys. Chem. 108B 2261

51. McCord J M and Fridovich I 1968 J. Biol. Chem. 243 5753

52. Chaki N K and Vijayamohanan K 2002 Biosens. Bioelectron. 171

53. Lisdat F, Ge B, Ehrentreich-Forster E, Reszka R and Scheller F W 1999 Anal. Chem. 711359

54. Gobi K V and Mizutani F 2000 J. Electroanal. Chem. 484172 